Research Article

\title{
Exploring the Determinants Associated with Adoption of Modern Methods of Family Planning among Married Women
}

\author{
Sayid Veg', Naveen Pareek ${ }^{2}$, Santosh Sajjan ${ }^{3}$ \\ ${ }^{1}$ Principal, Laganshah memorial Nursing college, Makkrana, Dist. Nagaur, Rajasthan. \\ ${ }^{2}$ Professor, Sarvapalli Radhakrishnan University, Madyapradesh. \\ ${ }^{3}$ Asst. Professor, Sajjalashree Institute of Nursing, Navanagar, Bagalkot, Karnataka. \\ DOI: https://doi.org/10.24321/2348.2133.201906
}

\section{I $\quad \mathbf{N} \quad \mathbf{F} \quad \mathbf{O}$}

\section{Corresponding Author:}

Sayid Veg, Laganshah memorial Nursing college,

Makkrana, Dist. Nagaur, Rajasthan.

E-mail Id:

sayidveg09@gmail.com

Orcid Id:

https://orcid.org/0000-0001-6692-1505

How to cite this article:

Veg S, Pareek N, Sajjan S. Exploring the Determinants Associated with Adoption of Modern Methods of Family Planning among Married Women. Ind J Holist Nurs 2019; 10(2\&3): 1-5.

Date of Submission: 2019-10-19

Date of Acceptance: 2019-12-09

\section{$\begin{array}{llllllll}\mathbf{A} & \mathbf{B} & \mathbf{S} & \mathbf{T} & \mathbf{R} & \mathbf{A} & \mathbf{C} & \mathbf{T}\end{array}$}

Background: Modern contraceptive methods use is cost effective strategy and it is an important effective public health interventions to avert unwanted pregnancies, reduce maternal mortality rate and in developing country, population explosion can be under control. There are numerous factors that contribute to the use of contraceptive methods among Indian married women. It is very crucial to identify such factors so that the major focus can be laid on such aspects to make the family planning projects of India more effective and successful.

Materials and Methods: The data regarding socio demographic factors or determinants was collected using structured interview schedule and the adoption of modern family planning methods was assessed by check list. The sample size was 200 married women between 18 to 45 years of age, 100 from rural areas and 100 from urban areas. The data was analyzed by descriptive statistics and inferential statistics, Chi square.

Result: Majority of subjects in rural area about $28(14 \%)$ mothers were adapted family planning methods and in urban area i.e. $48 \%$ (24\%) were adapted family planning methods in group I. whereas in group II in urban area 70 (35\%) were not adapted family planning methods, in rural area $54(27 \%)$ mothers were not adapted any type of family planning methods. A significant association was found between adoption of contraceptives and determinants among married women.

Conclusion: There are many factors significantly associated with adoption of family planning methods among married women.

Keywords: Modern Contraceptive Methods, Cost Effective Strategy, Determinants

\section{Introduction}

"Women have the right to know about the potential health benefits of birth spacing" - Jeff Spieler.
Maternal health is the most important aspect of any society. Maternal wellbeing is a significant determinant of familial, instructive, monetary, and natural improvement. Family 
planning through contraception offers women to have, chance to pick up time between pregnancies by choosing when to get pregnant in connection to their other life commitments. ${ }^{1}$ Take-up of current Family Planning (FP) techniques stays low in India. This might be related with high frequency of unintended pregnancies, dangerous premature births, and maternal mortality. Twenty Indian states have dipped below the 2.1 replacement rate level and are no longer contributing to Indian population growth. The total fertility rate of India stands at 2.2 as of 2017 . Four Indian states have fertility rates above 3.5 - Bihar, Uttar Pradesh, Meghalaya and Nagaland Of these, Bihar has a fertility rate of 4.0 births per woman, the highest of any Indian state. ${ }^{2}$

At the national level, as indicated by Ministry of wellbeing and family welfare (April 2006-07), the quantity of IUD inclusions have demonstrated an expansion of $2.1 \%$ over the comparing time of the earlier year. The significant states wherein the exhibition has declined are Bihar (-43.43.8\%), Assam (-14.7\%), Punjab (-6.5\%), Kerala (-4.9\%) and TamiNadu (-1.6\%), Karnataka (-4.2\%). The real States showing a superior exhibition is West Benga16.5\%), Jharkhand (15.9\%), Rajasthan (11.4\%), Madhya Pradesh (8.7\%), Gujarat (6.5\%), Haryana (6.2\%), Uttarpradesh (4.8\%), Andhrapradesh (1.3\%) and Chhattisgarhi (1.1\%). ${ }^{3}$

The United Nations Population Fund (UNFPA) says that, "If all women with an unmet need for contraceptives were able to use modern methods, an additional 24 million abortions (14 million of which would be unsafe), 6 million miscarriages, 70,000 maternal deaths and 500,000 infant deaths would be prevented". ${ }^{4}$

The Millennium Development Goal (MDG) 5 targets improving maternal wellbeing and decreasing maternal mortality. Some family planning strategies, for example, condom utilization can shield people from Sexually Transmitted Infections (STIs) including HIV/ AIDS. Family planning has likewise been found to advance sex equity just as advance instructive and financial strengthening for ladies. ${ }^{5}$

\section{Methods}

\section{Research Design and Sampling Technique}

A Cross sectional descriptive design was selected for the present study. Convenient Sampling technique was used to select 200 married women as the study samples from the rural and urban areas, 100 from rural areas and 100 from urban areas. Prior to actual data Collection, the investigator obtained permission from the Medical officer, Jusari, PHC Tehsil and Medical officer, Makrana CHC, Makarna, Nagaur district and Gram panchayat members. Participants consent was taken for willingness in research study. Data was collected by using closed ended structured knowledge questionnaire and attitude scale, data collected for about 65 days, which begins from 15-11-2018 to 20-1-2019.
The people were interviewed from 9am to $5 \mathrm{pm}$, based on their availability and convenience. Every day 4 people were interviewed and co-operation was obtained from the subjects and it made easier for the investigator to gather the necessary information.

\section{Following Questionnaire?}

\section{Types of Family Planning Methods}

1. How to prevent increasing population in India?

a. Using correct family planning methods to avoid pregnancy

b. Using communication skills

c. Using improper knowledge

d. Using unrelated surgey

2. What are family planning methods?

a. Methods use to prevent pregnancy

b. Methods use to increase knowledge

c. Methods use to improve skills

d. Methods use to communication

3. What are types of family planning methods?

a. Temporary and permanent family planning methods

b. Biological \& thermal family planning methods

c. Environmental \& geographical family planning methods

d. Physical family planning methods

4. How the family planning methods will influence on health of women?

a. Lead better and healthy life

b. Lead difficult and unhealthy life

c. Lead poor lifestyle \& poor life

d. Lead insufficient life \& unsatisfactory life

5. Why one should adopt the family planning methods?

a. To have small family norm

b. To have more children's

c. To have male children's

d. To have big family

6. Which of the following is the ill effect on women if she did not adopt the family planning method?

a. Affects mother's health

b. Affects mother's social image

c. Affects mother's beauty

d. Affects mother's personality

7. What is the advantage of diaphragm?

a. It can be used immediately after delivery to prevent pregnancy

b. It can be used after sexual intercourse

c. It can be used in pregnancy.

d. It can be used in non reproductive age 
Samples selected for the study includes married women residing in rural and urban areas of Nagaur, District Rajasthan. The present study was conducted in rural PHC Jusari, Makrana which is a rural area of district nagaur, Rajasthan and Goura Baas, which is an urban area of Makrana, district Nagaur, Rajasthan. The data regarding socio demographic factors or determinants was collected by face to face using structured interview schedule and the adoption of modern family planning methods was assessed by check list in present study the data was collected by interview technique by using structured interview schedule.

\section{Statistical Tool Used to Analyze the Data}

The data obtained was analyzed in terms of achieving the objectives of the study using descriptive and inferential statistics. Calculation of mean, standard deviation of knowledge score. Application of ' $Z$ '- test for comparison of knowledge regarding modern methods of family planning between rural and urban married methods of family planning. Application of chi-square test to find the association between socio -demographic variables with knowledge scores.

\section{Ethical Consideration}

The present study was accepted from institutional ethical committee. Clearance certificate was submitted with synopsis of study. Permission obtained from Medical officer, Jusari, PHC Tehsil and Medical officer, Makrana CHC, Makarna, Nagaur district and Gram panchayat members. Participants consent was taken for willingness in research study.

\section{Inclusion Criteria}

The study includes the married women, who are;

- Able to understand English or Hindi.

- Available at the time of data collection.

- In the age group of 18-45 years.

\section{Exclusion Criteria}

The study excludes the people, who are;

- Not willing to participate in the study.

- Physically and mentally challenged.

- Married women who have undergone hysterectomy.

- Suffering from chronic illness.

\section{Result}

According to fig no: 1 depicts that in rural area majority of subjects 28 (14\%) mothers were adapted family planning methods. In urban area i.e. $48 \%$ (24\%) were adapted family planning methods. whereas in group II in urban area 70 (35\%) were not adapted family planning methods, in rural area $54(27 \%)$ mothers were not adapted any type of family planning methods.

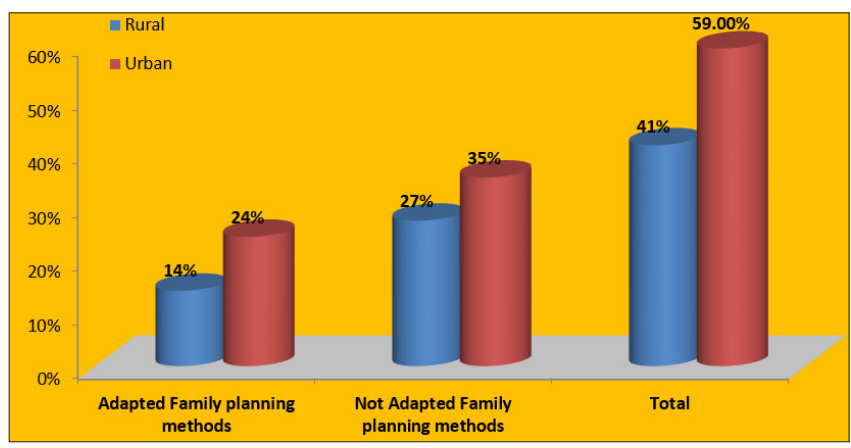

Figure I.Distribution of married women according to their place of residence and adoption of family planning methods

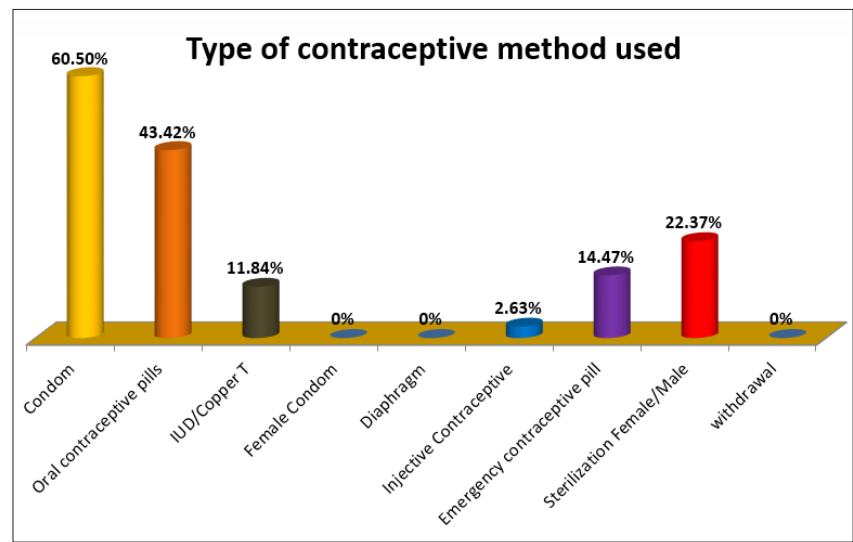

Figure 2.Distribution of married women according to their use of modern contraceptive methods

According figure 2, depicts the comparison between use of modern contraceptive methods among urban and rural married women shows that place of residence is a significant determinant in use of modern contraceptive methods. The use of modern contraceptive methods is more in urban married women as compared to rural married women. A significant association was found in place of residence $(P<$ 0.0365 ) and use of modern contraceptive methods among married women.

Table I.Association between determinants and use of modern contraceptive methods among married women

\begin{tabular}{|c|c|c|c|c|c|c|}
\hline S. No. & $\begin{array}{c}\text { Socio demographic } \\
\text { variable }\end{array}$ & DF & $\begin{array}{c}\text { Chi-square } \\
\text { value }\end{array}$ & p-value & Table value & $\begin{array}{c}\text { Significance of } \\
\text { association }\end{array}$ \\
\hline 1. & Place of residence & 1 & 8.822 & 0.0365 & 3.84 & Significant \\
\hline 2. & Age & 2 & 7.438 & 0.012 & 5.99 & Significant \\
\hline 3. & Educational status & 2 & 6.326 & 0.042 & 5.99 & Significant \\
\hline
\end{tabular}




\begin{tabular}{|c|c|c|c|c|c|c|}
\hline 4. & Religion & 2 & 2.86 & 0.15 & 5.99 & NS \\
\hline 5. & Number of live children & 1 & 4.346 & 0.037 & 3.84 & Significant \\
\hline 6. & Family monthly income & 4 & 21.09 & 0.000 & 9.49 & Significant \\
\hline 7. & Occupational Status & 4 & 17.655 & 0.001 & 9.49 & Significant \\
\hline 8. & $\begin{array}{c}\text { Age at the time of } \\
\text { marriage }\end{array}$ & 2 & 6.182 & 0.086 & 5.99 & Significant \\
\hline 9. & $\begin{array}{c}\text { Marital Duration in } \\
\text { years }\end{array}$ & 2 & 9.745 & 0.045 & 5.99 & Significant \\
\hline 10. & $\begin{array}{c}\text { Experience of child } \\
\text { death }\end{array}$ & 1 & 3.607 & 0.824 & 3.84 & NS \\
\hline 11. & Partner's approval & 1 & 5.776 & 0.016 & 3.84 & Significant \\
\hline 12. & $\begin{array}{c}\text { Exposure to mass } \\
\text { Media }\end{array}$ & 3 & 9.68 & 0.019 & 7.89 & Significant \\
\hline 13. & Socio economic status & 2 & 2.568 & 0.463 & 5.99 & NS \\
\hline
\end{tabular}

The other determinants: Age $(P<0.012)$,, educational status $(P<0.042)$, occupational status $(P<0.001)$, Number of live children $(P<0.037)$, Family monthly income $(P<0.000)$, Age at the time of marriage $(P<0.036)$, Duration since marriage $(P<0.045)$, partners approval $(P<0.016)$ and exposure to mass media $(P<0.019)$ were found to have significant association with use of contraceptives among married women.

\section{Discussion}

Among a sample of 200 married women only 76 married women used modern contraceptive methods. Among them $60.5 \%$ (40) women used condoms, $43.42 \%$ (33) women used oral contraceptive pills, $11.84 \%$ (9) women used Intrauterine devices/ copper T, $2.63 \%$ (2) used injectable contraceptives, $14.47 \%$ (11) used emergency contraceptive pills, $22.37 \%$ (17) used sterilization methods. None of the married women among the samples used female condom, diaphragm or withdrawal method of contraception methods. A study conducted by Mustafa R, Afreen U, Hashmi HA, data reveals contraceptives knowledge, attitude and practice among rural women in which there was a low contraceptive use of women despite of good knowledge in the rural areas due to negative attitude towards contraception by women's as well as their husbands. ${ }^{6}$

$60(30 \%)$ married women had poor knowledge among which 19 were $(9.5 \%)$ were from urban area and 41 (20.5\%) were from rural area. 87 (43.5\%) married women had average knowledge among which 61 (30.5\%) were from urban area and $26(13 \%)$ were from rural area. 53 (26.5\%) married women had good knowledge among which 38 were $(19 \%)$ were from urban area and 15 (12.5\%) were from rural area.

Similar results were obtained in a study conducted to assess the knowledge, attitude and practice of family planning among 50 married Meitei women in Tezu village Manipur in which. $60 \%$ of the respondent approved towards family planning $28 \%$ is disapproved to it where as $12 \%$ does not know. In another descriptive study the majority of them had knowledge about oral contraceptive pills (92.9\%), injectable (89.4\%) and IUD (89.4\%). ${ }^{7}$

\section{Conclusion}

In spite of the huge advantages of family planning administrations, the use of contraceptives still stays low in India. This has come about into high paces of undesirable pregnancies, insufficient conveyances, hazardous premature births and maternal mortalities. There is significant association found between place of residence and adoption of modern family planning methods. The adoption of contraception is more in urban areas as compared to rural areas. Such factors must be considered and used in strengthening the family planning strategies in India Hence more focus should be on rural married women to successfully implement the family planning methods to each the goals of family planning in India. The identified determinants. Should be used to focus the areas of concern in dealing with various problems that interfere with successful achievement of family planning strategies.

\section{Conflict of Interest: None}

\section{References}

1. Eliason S, Awoonor-Williams JK, Eliason C, Novignon J, Nonvignon J, Aikins M. Determinants of modern family planning use among women of reproductive age in the Nkwanta district of Ghana: A case-control study. Reprod Health 2014; 11(1): 65. Available from: https://reproductive-health-journal.biomedcentral. com/articles/10.1186/1742-4755-11-65 [PubMed/ Google Scholar].

2. Apanga PA, Adam MA. Factors influencing the uptake of family planning services in the Talensi District, Ghana. Pan Afri Med J 2015; 20: 10. Available from: 
http://www.panafrican-med-journal.com/content/ article/20/10/full/ [PubMed/ Google Scholar].

3. Muanda MF, Ndongo GP, Messina LJ, Bertrand JT. Barriers to modern contraceptive use in rural areas in DRC. Cult Health Sex 2017; 19(9): 1011-1023. Available from: https://www.tandfonline.com/doi/full/10.1080 /13691058.2017.1286690 [PubMed/ Google Scholar].

4. Nelson AL, Massoudi N. New developments in intrauterine device use: focus on the US. Open Access $J$ Contracept 2016; 7: 127-141. Available from: https:// europepmc.org/article/med/29386944 [PubMed/ Google Scholar].

5. Cates W, Karim QA, El-Sadr W, Haffner DW, KalemaZikusoka G, Rogo K et al. Family planning and the millennium development goals. Science 2010; 329: 1603. Available from: https://science.sciencemag. org/content/329/5999/1603.long [PubMed/ Google Scholar].

6. Mustafa R, Afreen U, Hashmi HA. Contraceptive knowledge, attitude and practice among rural women. $J$ Coll Physicians Surg Pak 2008; 18(9): 542-545. [PubMed, Google Scholar].

7. Mao J. Knowledge, attitude and practice of family planning: A study of Tezu Village, Manipur (India). Internet Journal of Biological Anthropology 2007; 1. Available from: https://print.ispub.com/api/0/ispubarticle/3999 [ResearchGate/ Google Scholar]. 